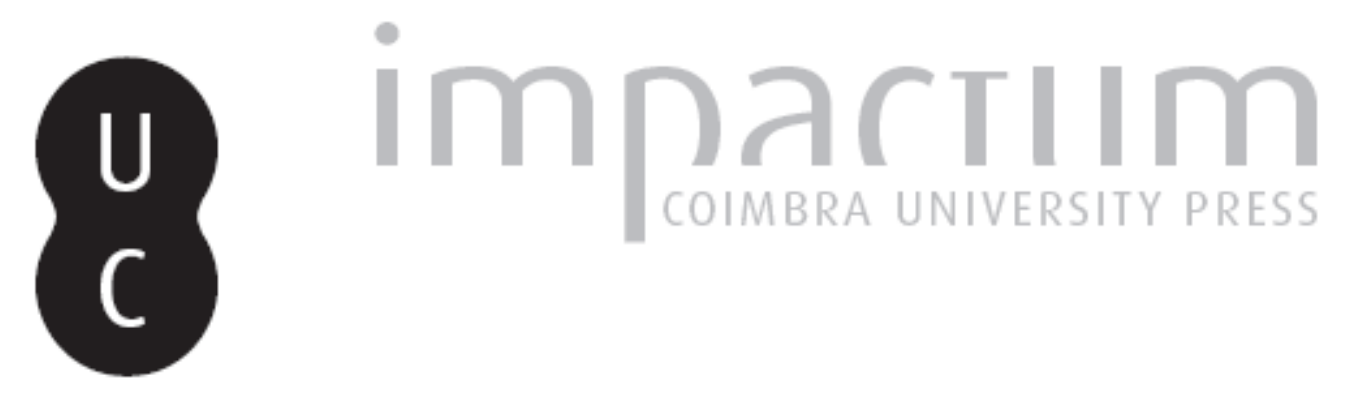

\title{
Pensar a cidade
}

\section{Autor(es): $\quad$ Ferreira, Raúl Hestnes}

Publicado por: Editorial do Departamento de Arquitectura

URL persistente:

URI:http://hdl.handle.net/10316.2/37472

DOI:

DOI:http://dx.doi.org/10.14195/0874-6168_4_6

Accessed : $\quad$ 26-Apr-2023 12:18:09

A navegação consulta e descarregamento dos títulos inseridos nas Bibliotecas Digitais UC Digitalis, UC Pombalina e UC Impactum, pressupõem a aceitação plena e sem reservas dos Termos e Condições de Uso destas Bibliotecas Digitais, disponíveis em https://digitalis.uc.pt/pt-pt/termos.

Conforme exposto nos referidos Termos e Condições de Uso, o descarregamento de títulos de acesso restrito requer uma licença válida de autorização devendo o utilizador aceder ao(s) documento(s) a partir de um endereço de IP da instituição detentora da supramencionada licença.

Ao utilizador é apenas permitido o descarregamento para uso pessoal, pelo que o emprego do(s) título(s) descarregado(s) para outro fim, designadamente comercial, carece de autorização do respetivo autor ou editor da obra.

Na medida em que todas as obras da UC Digitalis se encontram protegidas pelo Código do Direito de Autor e Direitos Conexos e demais legislação aplicável, toda a cópia, parcial ou total, deste documento, nos casos em que é legalmente admitida, deverá conter ou fazer-se acompanhar por este aviso. 


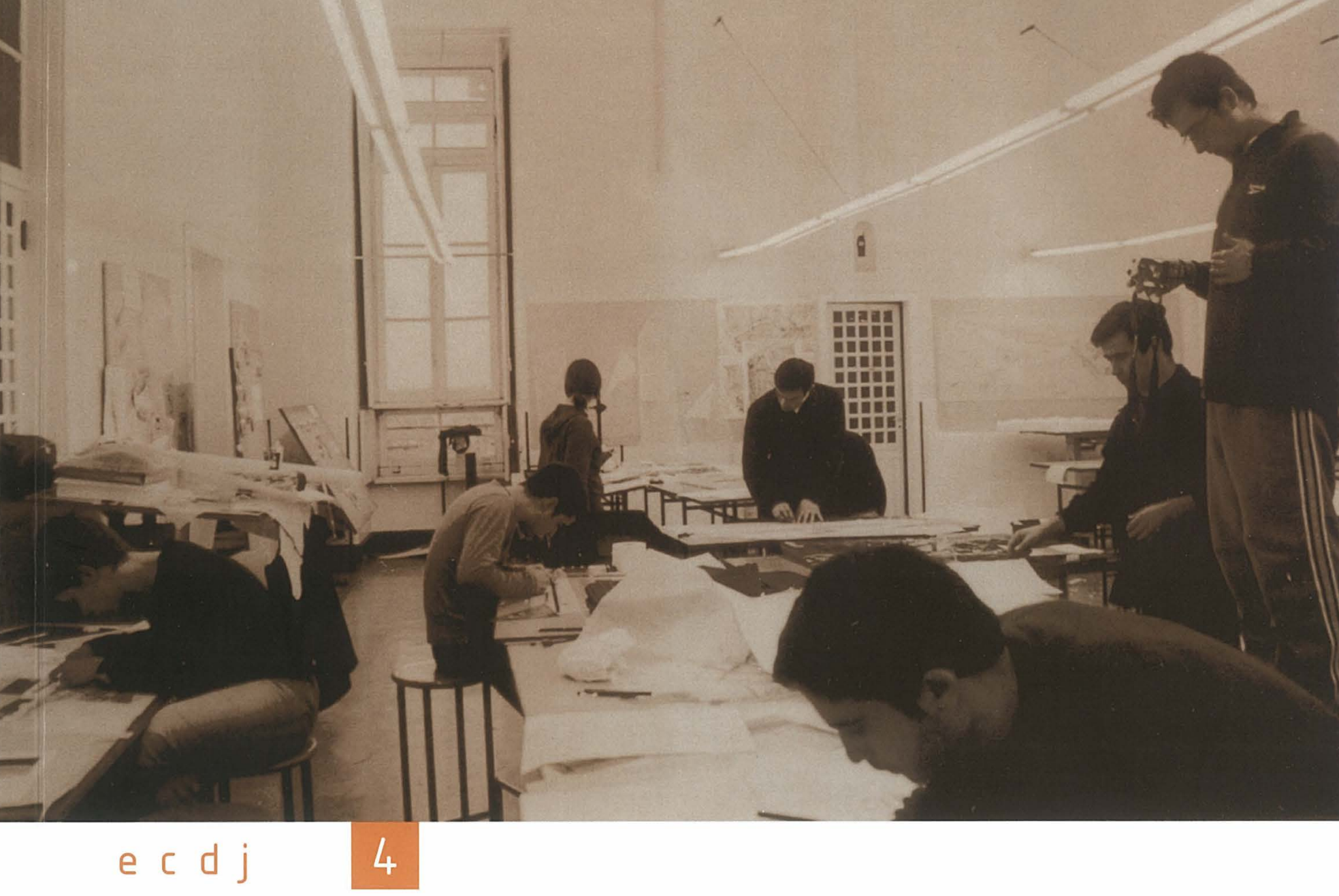

fctuc | departamento de arquitectura

coimbra: um novomapa

manuel gallego

workshop internacional de arquitectura

manuel solà-morales

manuel graça dias

гаúl hestnes fеггеiга

sergio fernandez

álvarosiza entrevista

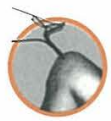




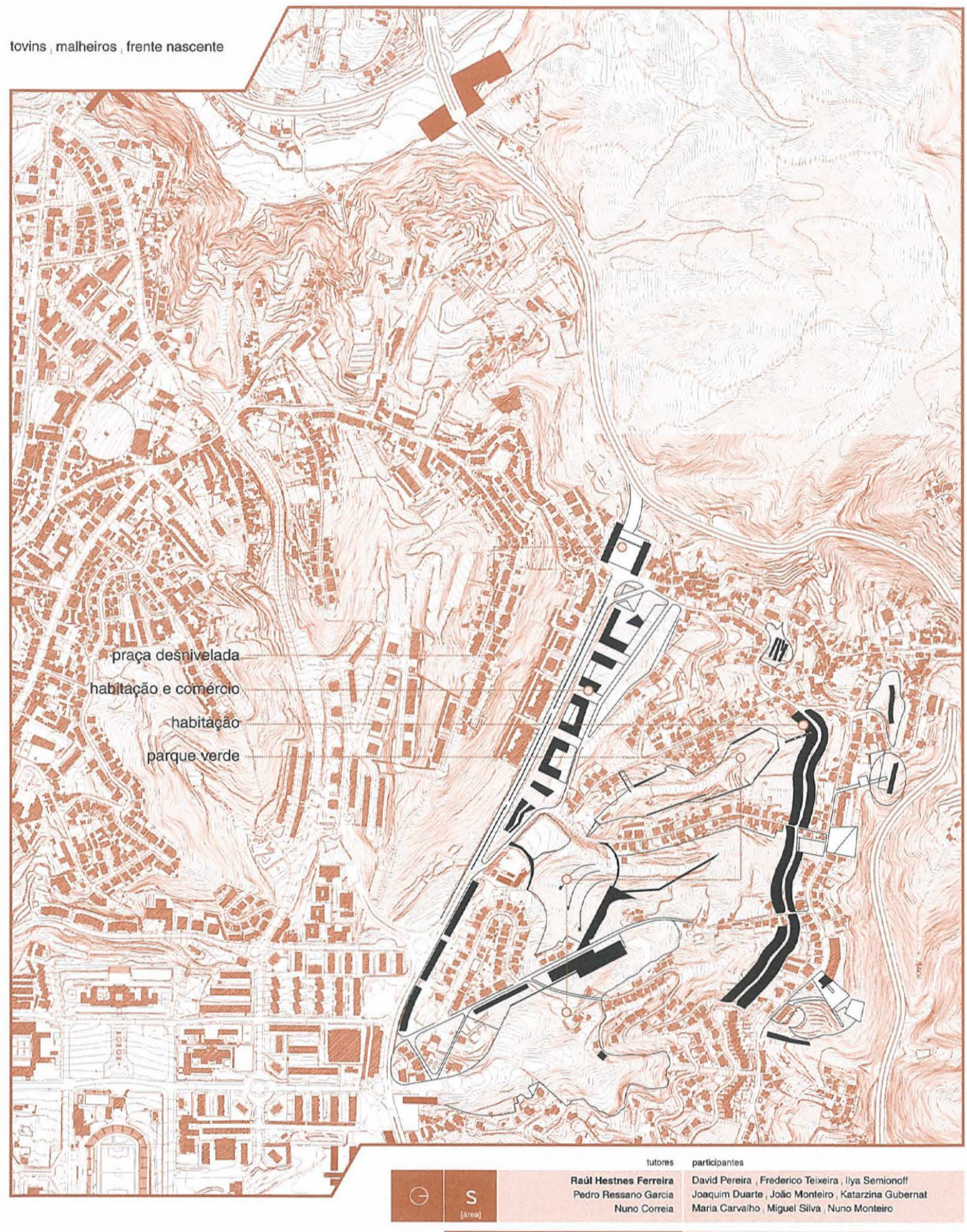



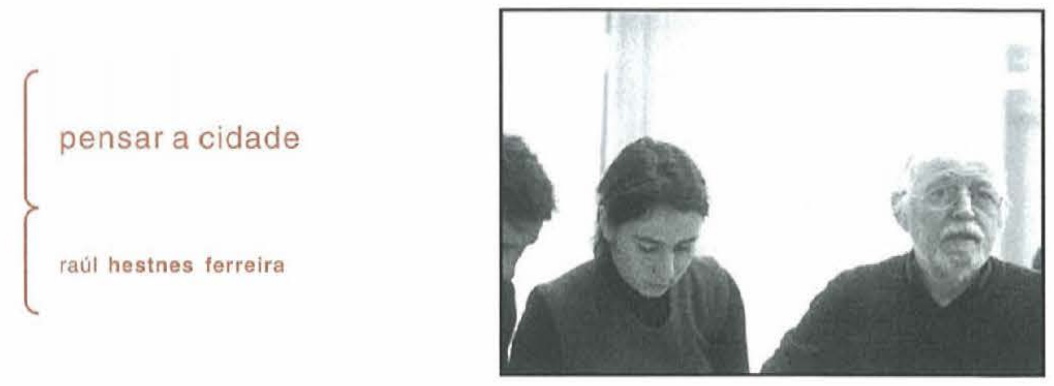

\section{introdução}

Este Encontro permitiu, baseado em estudos da expansão urbana de Coimbra, reflectir sobre o papel do arquitecto na concepção da cidade portuguesa, tendo como referência a prática corrente, de cariz normativo, comparativamente com as exigências que a criação e o desenho de novos espaços urbanos impõem.

> A área de estudo de TOVIM, na proximidade de SOLUM, a nova e curiosa "baixa" de Coimbra, confiada ao grupo que coordenámos neste Workshop, está no limite da progressão da cidade para nascente (antes dos elevados declives que lhe sucedem), e os dois tipos de ocupação que integra elucidam sobre alguns problemas inerentes à expansão das cidades portuguesas.

> Uma das ocupações, a "espontânea", resultou da acumulação, durante anos, de construções, casa a casa, nas cumeadas das colinas próximas, mais tarde "regrada" para tentar evitar o agravamento dessa expansão sobre encostas e linhas de água. A outra ocupação, por contraste, exerceu-se pela implantação linear de edifícios de grande porte num vale, planeada com a evidente contribuição de arquitectos, junto a taludes resultantes do corte da encosta poente, que posteriormente se desmoronou com as chuvadas deste ano.

> Qualquer das intervenções, a "espontânea" e a "planeada", balizam caricaturalmente os problemas da cidade portuguesa, entre o desejo do cidadão comum de construir, onde e como quiser, a casinha (remetendo para questões de ideário e modelo de vida) e o dos promotores, preocupados em rendibilizar o investimento com elevadas volumetrias.

\section{a cidade e o arquitecto}

> Quando descançamos de séculos de viagens e sofrimentos, diálogos e transações, à beira mar, com diferentes povos, seria o momento de nos debruçarmos sobre o nosso espaço para saber que modo de vida e sociedade queremos, e que cidade queremos, embora a margem de manobra para traçar o nosso destino como comunidade cultural seja limitado.

> Se mesmo o humilde FENO DE PORTUGAL não escapa às multinacionais, e as estruturas sociais e económicas do nosso território estão mais que condicionadas, a possibilidade de criar uma cidade harmoniosa e humanista concebida por arquitectos e ajustada a uma vivência estimulante, afigura-se quase impossivel. 
> Aliás, a mão do arquitecto na definição da estrutura da cidade portuguesa e suas tipologias foi, no século $X X$, (com raras excepções), muito limitada, dada a falência de projectos urbanos formalmente marcantes (lembremo-nos do Plano de De Groer em Coimbra) que rapidamente foram ultrapassados pela conjuntura e se converteram, em regra através da sua adulteração, em instrumento de construtores-investidores, para criar uma espécie de cidade desnorteada, a cidade que Crane designou por Frankenstein.

> Para alterar este processo, necessário seria confrontar as imagens dos arquitectos com os programas de promotores e decisores administrativos e, quiçá, dos utentes, para avaliação de propostas de desenho de cidade, sem evitar tensões inevitáveis, para as clarificar, pois hoje, quando os arquitectos intervêm em grande escala no tecido urbano, ou andam a reboque de interesses prevalecentes, ou ignoram-nos nas suas propostas, sem beneficiar os utentes.

> Reconhecer a importância da economia, constitui um factor a integrar na concepção da nova cidade, necessariamente centrada numa vertente utópica e nas experiências válidas do nosso meio urbano. Poder-se-ía partir dos que planearam ou desenharam a cidade, e cuja reflexão tenha sido motivada teoricamente, para repensar a sua estrutura geral.

> Para além de factores extrínsecos, o desenho de grandes conjuntos pressupõe uma investigação e uma mentalidade criadora de sistemas que ultrapassam a da prática corrente da arquitectura, mais preocupada com a afirmação do "objecto". As dificuldades dos estudos à escala da cidade não podem ser minimizadas, dado que as exigências dum mundo aberto, em transformação, como é o nosso, coloca questões sobre os modelos adequados, e sobre a capacidade de evolução desses modelos não finitos, que devem integrar espinhas dorsais estruturantes de corpos em expansão.

> Criem-se pois, a par de edifícios que transportem um sentido urbano, novos aglomerados não marcados por volumes e espaços inexpressivos e repetitivos, mas que integrem uma concepção espacial e arquitectónica complexa e elaborada (que sempre distinguiu a urbe) e uma aptidão natural para a vivência urbana. Na sua concepção não podemos esquecer, nem os modelos, estruturas e tipologias consagrados pela história, nem propostas morfológicas claras e originais, que não sejam loteamentos de uma geometria primária, mas antes propostas inventivas nascidas da reflexão e da capacidade para intuir, desenhar e olhar criticamente a cidade.

> Hoje ninguém duvida de que o papel inventivo e criador do arquitecto, pela sua formação e prática, é essencial para a consecução desses objectivos, e acrescentamos até que ele terá assumido uma neutralidade excessiva, estando demasiado distante deste processo,

> Sem subscrever o messianismo dos arquitectos, pois muito há a dizer sobre aspectos negativos da sua actuação, sobretudo quando no século XX assumiu, com um certo autismo derivado de convicções profundas, a defesa duma renovação total do meio urbano e do modo de habitar a cidade que o ambiente da época não soube discutir por incapacidade geral da sociedade para esse diálogo. 

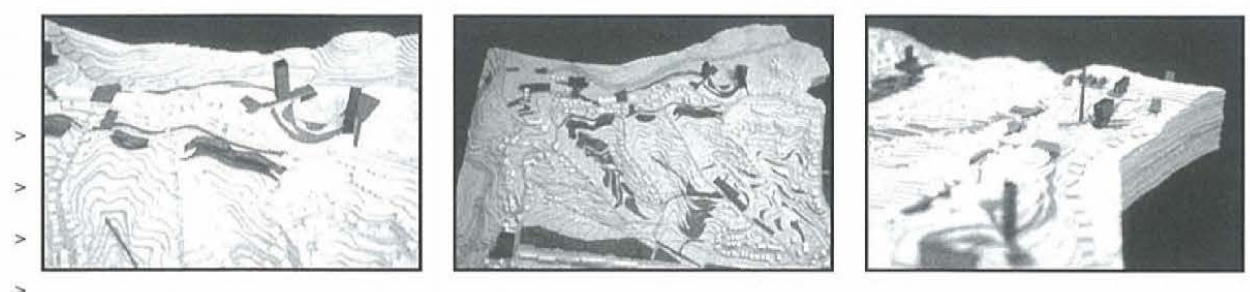

$>$

> Mas hoje o arquitecto deveria de novo desempenhar o papel que lhe cabe, propondo idéias e imagens que suscitem a crítica, não só dos cidadãos comuns, mas também das instituições, quer das orientadas para o bem público, como daquelas, cada vez mais centralizadas, cuja capacidade económica e poder são fundamentais para o processo urbano.

> Como referência da forma de actuação em áreas que necessitam duma intervenção reabilitadora, reportamo-nos aos objectivos propostos para a zona de TOVIM, que ocupou o nosso grupo de trabalho neste Workshop.

> O objectivo do estudo, segundo os parâmetros da ocupação existente, foi o de criar uma maior diversidade tipológica dos espaços urbanos, harmonizando-os com os volumes e espaços existentes, definindo a localização da volumetria, institucional e residencial, de acordo com a tipologia de espaços urbanos e verdes a propôr.

> Em TOVIM, simularam-se formas de intervenção em estruturas urbanas paralelas às que se verificariam numa situação real, para corrigir expansões urbanas carentes na sua estrutura programática e espacial. Com um mínimo de bom senso, propôs-se que os volumes a introduzir corrigissem o programa de edificações da área, introduzindo novas escolas, centros de saúde e áreas desportivas.

> Quanto à tipologia de ocupação, sugeriu-se a criação de espaços verdes e urbanos necessários à definição de um sistema urbano coerente, de que participaria, por exemplo, um largo definido por construções de baixa altura, a NE do núcleo, para festas e feiras ao ar livre do núcleo em que se insere, pracetas, com construções de pequeno volume, para reforçar o sentido linear dos edifícios de grande porte a poente e no final deste conjunto, a norte, uma Praça volumetricamente trabalhada na sua complexidade.

> Nas cumeadas a nascente, entendeu-se que deveria haver um esforço de agregação das construções existentes, polarizando-as nalguns locais e impedindo a ocupação de outros, para reforçar os espaços verdes existentes, criando deste modo um ritmo contrapontístico na ocupação das mesmas, e reforçando alguns pontos estratégicos, no limite da área a ocupar, com construções de altura superior às restantes.

> Dado o modo como ocorre o crescimento da cidade em Portugal julgamos que, mesmo o tipo de "correcções pontuais" sobre um território já ocupado como o que foi equacionado neste trabalho de Workshop, embora possa traduzir uma melhoraria da qualidade dos núcleos projectados, não poderá nunca ter os mesmos resultados que uma concepção global num território não comprometido com uma ocupação anterior, que fosse objecto de uma acção integrada e teoricamente fundamentada. 